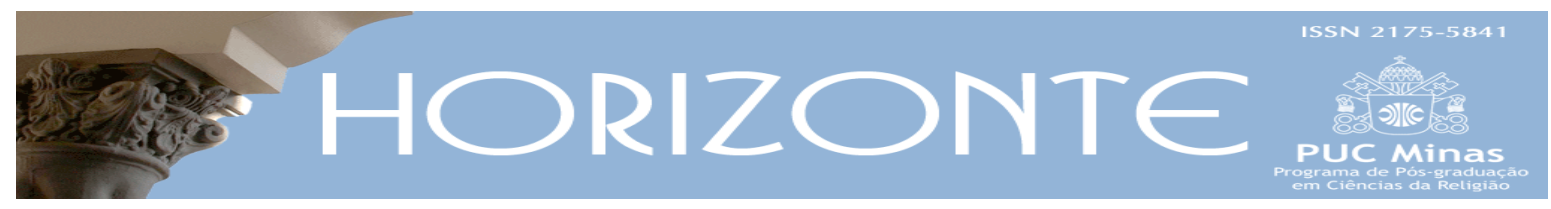

Comunicação

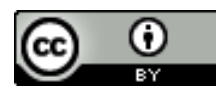

DOI - 10.5752/P.2175-5841.2019v17n53p1294

\title{
O capelão como mediador: revisão integrativa
}

\author{
The Chaplain as a mediator: an integrative review
}

\author{
Eliane Florencio Gama* \\ Thamires Fiorentino Jarra**
}

\begin{abstract}
Resumo
As mudanças observadas na estrutura sociocultural desde os tempos bíblicos até os dias atuais determinaram o desdobramento das diferentes áreas de atuação da Capelania/Aconselhamento, tais como nas áreas Hospitalar, Militar, Carcerária, Empresarial, dentre outras. Apesar dessa diversidade de áreas de atuação pode-se destacar uma situação comum: os conflitos interpessoais. Uma das possibilidades de intervir em situações de conflito é a Mediação informal, que se caracteriza pela atuação de um terceiro facilitador, que auxilia na solução amigável de conflitos. O objetivo do presente est udo foi quantificar, listar e analisar a literatura sobre a prática da Mediação Informal na Capelania/Aconselhamento. Foi utilizado o método da revisão integrativa, buscando dados nas seguintes bases eletrônicas Portal de Periódicos da CAPES; Scientific Eletronic Library online-Scielo; Science Direct e Google Acadêmico. Apenas seis artigos apresentaram informações sobre a elaboração de programas e estratégias de mediação de conflitos no âmbito carcerário, corporativo e hospitalar por iniciativa de serviços ou setores de Capelania. Além disso chama a atenção que em apenas uma dessas iniciativa houve um preparo específico dos capelães para mediação, realizado por uma ONG canadense que educa, treina e equipa nos moldes da justiça restaurativa, com particular atenção a área da capelania.
\end{abstract}

Palavras-chave: capelania; aconselhamento pastoral; mediação; resolução alternativa de conflitos.

\begin{abstract}
The development observed in the sociocultural structure from Biblical times to the present day have determined a widely of areas of Chaplaincy/Counseling, such as Hospital, Military, Prison and Corporate. In spite of this diversity of areas of action, a common situation can be pointed out in the activity of the chaplain/counselor: interpersonal conflicts. One of the possibilities of intervention in conflict problems is informal mediation, which is characterized by the intervention of a third party facilitator, who facilitate the holding of the talks of the conflicting parts. The present study quantified, listed and analyzed the literature on the practice of informal mediation in Chaplaincy/Counseling, to understand the chaplain/counselor's possibilities of acting as an informal mediator. To achieve this target, the integrative review method was used, searching data in the following electronic databases CAPES Portal of Periodicals; Scientific Eletronic Library online-Scielo; Science Direct and Google Scholar. Only six articles presented information on the elaboration of programs and strategies for conflict mediation in prisons, corporations and hospitals based on the initiative of services or sectors of Chaplaincy. In addition, it is worth noting that in only one of these initiatives had a specific preparation of the chaplains for mediation, by a Canadian nongovernmental organization committed to educating, training and equipping in the area of restorative justice, with particular attention to the chaplaincy area.
\end{abstract}

Keywords: chaplaincy; pastoral counseling; mediation; alternative dispute resolution.

Comunicação submetida em 26 de maio de 2019 e aprovada em 30 de agosto de 2019.

* Doutora em Ciências Morfofuncionais pela Universidade de São Paulo. Especialista em Aconselhamento e Capelania pela Faculdade Batista do Paraná. Professora no Programa de Doutorado em Educação Física da Universidade São Judas. País de origem: Brasil. E-mail: efgama@profaeliane.net

** Graduada em Direito, com experiência em mediação de conflitos. Mestranda em Ciências do Envelhecimento. País de origem: Brasil.

Horizonte, Belo Horizonte, v. 17, n. 53, p. 1294-1314, maio/ago. 2019 - ISSN 2175-5841 


\section{Introdução}

A Capelania, enquanto atividade de assistência espiritual com fundamentos bíblico-teológicos, embora presente tanto no Antigo como no Novo Testamento, não aparece com esse termo específico. No livro de Juízes (cap. 17) observa-se a descrição da contratação de um levita como sacerdote particular de um homem; já no livro de 1 Reis (cap. 22) os profetas eram líderes espirituais que davam suporte ao exército em guerra. No Novo Testamento duas passagens chamam a atenção por sua natureza de assistência e acolhimento ao próximo. A Parábola do Bom Samaritano (Lc 10) e o texto sobre o Grande Julgamento (Mt 25) descrevem exemplos de atividades típicas do capelão: assistência e cuidado, visitação, auxílio aos necessitados (ALVES, 2017).

As mudanças socioculturais que transcorreram desde os tempos bíblicos até os dias atuais moldaram as atividades da Capelania, que a partir das necessidades específicas de instituições ou grupos sociais, delinearam áreas de atuação com características particulares, sendo possível exercer diferentes aspectos dessa atividade, tais como: Capelania Hospitalar, Capelania Militar, Capelania Carcerária, Capelania Universitária, Capelania Escolar, Capelania Empresarial, Capelania Funerária, Capelania Resgate, Capelania Ambiental, Capelania Esportiva, Capelania Pós-Desastre, Capelania Parlamentar, dentre outras (ASSOCIAÇÃO DE CAPELANIA DO BRASIL; ALVES, 2017). Cada um desses campos de atuação apresenta características próprias no que se refere aos problemas e as estratégias de intervenção/aconselhamento necessárias.

\section{Conflitos interpessoais}

Os conflitos interpessoais são ocorrências sociais entre duas ou mais pessoas. Os conflitos dualísticos são caracterizados por um nítido comportamento opositor; já os conflitos entre grupos se manifestam por atitudes negativas direcionadas aos membros ou representantes de um outro grupo (LAURSEN; HARTUP; KOPLAS, 1996). E isso se deve a pluralidade de discursos, ideias e 
crenças da sociedade contemporânea. Cada ente funciona de modo autônomo, com significados únicos para uma mesma situação.

Apesar de serem situações tensas, os conflitos e o seu gerenciamento fazem parte das questões inerentes aos relacionamentos humanos e não são necessariamente nem ruins nem bons, pois a depender dos seus resultados podem ser tanto construtivos como destrutivos. Geralmente os conflitos resolvidos a partir de uma negociação tendem a ser mais positivos do que os solucionados por coerção. A depender dos atores envolvidos no conflito, podem-se observar diferentes estratégias de resolução. Os conflitos conjugais e entre amigos tendem a priorizar estratégias que minimizem os prejuízos ou até mesmo o rompimento dos laços afetivos; já os comportamentos relacionados a conflitos entre colegas de trabalho ou membros de uma família podem ter como objetivo ganhos pessoais ou poder, em detrimento da manutenção dos relacionamentos (LAURSEN; HARTUP; KOPLAS, 1996; LAURSEN; HARTI, 2015).

Os conflitos são necessários para aprimorar os ajustes psicossociais, para desenvolver estratégias de convivência, entretanto, o excesso de conflitos pode sobrecarregar os mecanismos de enfrentamento; bem como a ausência de conflitos não oportuniza os desafios necessários para o desenvolvimento pessoal. A disputa, o conflito, a contenda figura como um cenário de discórdia recorrente na atividade do capelão. WILLEY (1989) aponta que os capelães muitas vezes estão em uma posição única e privilegiada para auxiliar as comunicações e as negociações entre as partes envolvidas num conflito/crise, seja no âmbito hospitalar, familiar, escolar, militar, dentre outros, podendo desse modo ser reconhecido como um mediador.

\section{Mediação}

SERRANO (1996) define a mediação como um processo de resolução de conflitos que se caracteriza pela presença de uma terceira parte que, não envolvida diretamente no conflito, interfere de forma neutra na tentativa de que as partes em contenda restabeleçam a comunicação. Braga Neto (2010) aponta que essa terceira 
parte deve ser "pessoa física, independente, imparcial, competente, diligente e escolhido em consenso", e acrescenta que a Organização das Nações Unidas (ONU) indica a mediação como a forma mais apropriada de promover a cultura da paz.

O processo de mediação pode ocorrer de forma estruturada, denominado de mediação formal ou de modo informal, a mediação informal. Na mediação formal o mediador é um especialista de um órgão oficial contratado para solucionar a disputa; já na mediação informal o mediador não representa nenhuma entidade específica (BERCOVITCH, 1992). Na mediação informal além de se observar a tendência de menor estigmatização social e maior economia financeira, destaca-se que é possível conseguir a solução do conflito em tempo menor que na mediação formal (FRADE, 2003; SPENGLER, MORAIS, 2008).

Com relação a atitude de neutralidade do mediador, essa posição não é unânime entre os estudiosos. ROTHMAN (2014) afirma que o mediador entra na mediação com seu próprio conjunto de experiências, emoções e preconceitos que são ativados pelo próprio conflito ou pelos conflitantes. E caso o mediador não reconheça seus próprios vieses a mediação seria prejudicada, mas se, no entanto, o mediador reconhecer suas próprias emoções e atitudes, esse movimento reflexivo de reconhecimento pode ser aproveitado para melhorar o processo de mediação. Ao envolver-se neste processo, o mediador usa a reflexividade como uma ferramenta para aumentar a autoconsciência e promover, o que o autor denominou de um "viés disciplinado". Desse modo, as partes em conflito e o próprio mediador conseguem ter uma visão mais sutil do conflito e uma melhor compreensão das necessidades, valores e significados da outra parte.

O mediador reflexivo consegue isso tanto demonstrando ele mesmo um comportamento reflexivo quanto encorajando as partes a terem a mesma atitude. Ainda segundo o autor, a mediação reflexiva, se bem-sucedida, poderá ampliar o conhecimento de um conflitante a respeito do outro e sobre ele mesmo, estimulando desse modo a vontade de transformar o conflito em um processo de aprendizagem colaborativa. 
A imparcialidade não deve ser confundida com uma atitude passiva por parte do mediador, antes: "o mediador deve participar ativamente do processo de negociação, a fim de eliminar eventuais distorções que rompam com o necessário equilíbrio que deve existir entre as partes" (LOPES, 2015). Observa-se, portanto, o princípio da multiparcialidade, onde o mediador toma partido por todos, ao invés de tomar partido de uma só ou nenhuma das partes, sendo assim multiparcial.

Nesse tema, Giessmann e Wils (2011) afirmam que o mediador deve se envolver com todas as partes, sem ser tido, por uma ou mais delas, como partidário, unilateral ou descomprometido. Essa multiparcialidade pode prolongar o processo de mediação e, nesse caso, espera-se que o mediador tenha uma forte liderança e que ajude a construir um processo firme, que inclui a formação de uma rede de suporte que forneça segurança para manter o processo em andamento no caso de falha temporária das negociações e mecanismos para superar e desbloquear as negociações bloqueadas.

A mediação informal vale-se fundamentalmente do diálogo e da empatia. Domingos e Freire (2009) destacam que nesse tipo de mediação há envolvidos sentimentos, fatos e experiências tanto dos conflitantes quanto do mediador. Retzingel e Scheff (2000) propõem que os ideais e as narrativas são elementos importantes nos conflitos, pois expressam os interesses políticos, econômicos, emocionais e relacionais. Entretanto, os autores presumem que grande parte das técnicas de mediação ignora as preocupações emocionais e relacionais dos conflitantes.

Existem diferentes escolas e modelos de mediação: Modelo de Harvard, baseada no interesse das partes envolvidas, sendo muito utilizada no setor empresarial; Negociação Cooperativa de Harvard, com enfoque no conflito como um problema mútuo entre as partes e busca a solução em que ambos "ganhem"; Mediação Transformativa, cujo objetivo é modificar a relação entre as partes, mesmo que não haja acordo; Mediação Circular-Narrativa, desenvolvida por Sara Cobb, que investe na possibilidade das partes encontrarem novo significado para 
uma realidade anterior, a partir de uma perspectiva diferente dos fatos narrados (FALECK; TARTUCE, 2014). Com relação a esses modelos ou estratégias, Braga Neto (2010) destaca a necessidade de o mediador capacitar-se e passar por treinamento específico com elementos teóricos e práticos com enfoque na ampliação de sua capacidade de escuta e autorreflexão, de modo a provocar a mesma capacidade nos mediados.

No Manual de Mediação Judicial (2016), no Anexo I, encontram-se as Diretrizes Curriculares do curso de capacitação dos terceiros facilitadores (conciliadores e mediadores), bem como as áreas de utilização da conciliação/mediação, além dos limites de atuação do terceiro facilitador.

Com relação aos cursos de capacitação é importante salientar que os requisitos para atuação específica como Mediador Judicial estão previstos no art. 11 da Lei 13.140/2015 (Lei de Mediação): "Poderá atuar como mediador judicial a pessoa capaz, graduada há pelo menos dois anos em curso de ensino superior de instituição reconhecida pelo Ministério da Educação e que tenha obtido capacitação em escola ou instituição de formação de mediadores, reconhecida pela Escola Nacional de Formação e Aperfeiçoamento de Magistrados - ENFAM ou pelos tribunais, observados os requisitos mínimos estabelecidos pelo Conselho Nacional de Justiça em conjunto com o Ministério da Justiça." Entretanto, o conciliador judicial pode ser qualquer pessoa que tenha interesse e disposição para se aperfeiçoar de acordo com a capacitação oferecida pelo local onde pretenda atuar. Nesse caso tanto o mediador quanto o conciliador atuam na esfera judicial, entretanto as estratégias de resolução de conflitos não necessariamente necessitam transitar na esfera judicial, sendo preferível que a contenda não se estenda até esse ponto.

\section{Mediação no aconselhamento e na capelania}

No Antigo Testamento observa-se um exemplo típico de atuação como mediador quando o Rei Salomão, conhecido por sua sabedoria, demonstrou grande 
habilidade na solução do conflito entre duas mulheres que se diziam mães do mesmo bebê (1 Rs 3). O conflito entre as pessoas continua sendo algo comum, contudo a complexidade dos relacionamentos interpessoais na sociedade contemporânea tem multiplicado a quantidade de conflitos, o que tem levado à busca de meios informais para a solução entre as controvérsias. Surge então nos EUA, no início do século XX, um movimento de apoio aos meios alternativos de solução de conflitos (Alternative Dispute Resolution, ADR - movement), onde o mediador é um facilitador da comunicação entre os envolvidos (DIAS, 2014).

Em termos teológicos o papel do mediador é centrado na figura de Jesus Cristo. Paulo afirma na primeira epístola a Timóteo que "há um só mediador entre Deus e os homens, Cristo Jesus, homem” (1 Tm 2:5), entretanto também exorta aos Romanos que "se possível, quanto depender de vós, tende paz com todos os homens" (Rm 12:18). Essa busca de convivência harmoniosa com todos, em muitos casos, pode requerer a assistência de uma terceira pessoa com posicionamento espiritual semelhante, o capelão/aconselhador. Aqueles que procuram um aconselhamento com viés religioso encontram na figura do capelão/aconselhador alguém com quem se identificam nas questões sagradas que permeiam seu contexto social (SOUZA, 2013).

Observa-se que a mediação informal está muito próxima do aconselhamento, pois o conselheiro apresenta o nítido papel de aconselhador e facilitador das relações interpessoais. Uma relação empática entre o conselheiro e aconselhado, pode predispor a um estado de ânimo propício ao diálogo e troca de ideias.

Entretanto, apesar de várias pessoas se disporem a realizar o trabalho de capelão, não há um preparo adequado para tal, mesmo na vigência de diversos cursos de Capelania oferecidos no Brasil. Alves (2017) argumenta que muitos dos cursos existentes não apresentam um projeto pedagógico adequado, e além disso o autor destaca a escassez de literatura de referência nacional que dê suporte a um capelão iniciante. $\mathrm{O}$ autor descreve em seu livro um projeto bem-sucedido em 
Capelania, denominado “A polícia e a igreja”. O programa refere-se a uma cooperação entre igrejas locais e a Polícia Militar do Estado de São Paulo, com o objetivo de promover a assistência espiritual aos integrantes dessa corporação. De modo mais específico o capelão, voluntário, deveria realizar entre os policiais militares, servidores civis e seus familiares, orientação e acompanhamento espiritual e atuar na mediação de conflitos.

Observa-se pelo exposto acima que há um campo amplo de possibilidades de atuação do capelão/aconselhador para a facilitação da resolução de conflitos interpessoais, entretanto, devido a especificidade da estratégia de mediação informal, esse processo em particular não deve ser aplicado de forma intuitiva, mas de modo estruturado, apesar de sua característica informal. Nessa perspectiva, esta revisão integrativa tem como objetivo quantificar, listar e analisar a literatura sobre a Mediação Informal na Capelania/Aconselhamento. Ademais, com esse estudo espera-se contribuir na ampliação das discussões sobre a diversidade de possibilidades no processo de atuação do capelão/aconselhador.

\section{Método}

Para alcançar o objetivo desse estudo, optou-se pelo método da revisão integrativa, visto ser uma forma de pesquisa que revisa, critica e sintetiza a literatura representativa sobre um tema de modo que novas perspectivas sejam geradas sobre o mesmo (TORRACO, 2005).

Foram analisados estudos de investigação publicados, selecionados a partir das bases de dados: Portal de Periódicos da CAPES; Scientific Eletronic Library online-Scielo; Science Direct e Google Acadêmico. Definiram-se os seguintes termos de busca: capelão (chaplain), capelania (chaplaincy), aconselhamento pastoral (pastoral care), mediação (mediation), mediador (mediator), conflitos (conflicts), mediação de conflitos (conflicts mediation), tratamento de conflitos (conflicts treatment); resolução alternativa de conflitos (Alternative Dispute Resolution Movement). Foram selecionados artigos originais, artigos de revisão, 
mini-revisão, comunicação breve e estudo de caso e foram excluídos os estudos que não identificavam ou não descreviam a atuação do capelão como mediador e os que estavam relacionados à mediação formal, no período de 2008 a 2018.

Numa primeira etapa foi feita a leitura dos títulos e resumos dos artigos para verificar a sua relação com o tema proposto nesse estudo. A partir dessa análise dos artigos encontrados, a amostra foi constituída por seis estudos de investigação, publicados sob a forma de artigo original. Foram elaborados dois quadros: um contendo a quantidade de referências encontrada em cada base de dados e outro com o título do artigo e resumo dos resultados dos estudos que continham alguma informação sobre a atuação do capelão/aconselhador como mediador.

\section{Resultados e discussão}

Após a busca nas bases de dados e aplicação dos critérios de inclusão/exclusão foram analisados seis artigos que apresentaram conteúdo relacionado aos objetivos do presente estudo. O Quadro 1 apresenta a quantidade total de artigos encontrados para cada combinação de palavras (português e inglês). Observa-se que o Portal CAPES e o Google Acadêmico são as bases de dados que fornecem maior quantidade de resultados, entretanto a base Google Acadêmico não apresenta recursos para filtrar as informações obtidas quanto ao tipo de material (artigo, livro, dissertação, tese...), dificultando a análise das produções uma a uma, pois a busca que retornou menor quantidade de resultados somou 1.200 produções. Desse modo, a quantidade de resultados obtidos no Google Acadêmico foi utilizada para dimensionar o volume de publicações no período de 10 anos, entretanto as obras não foram consultadas.

A combinação dos termos em português capelania AND mediação AND conflitos; capelania AND mediação AND conflitos resultou em apenas um artigo. Já a combinação dos mesmos termos em inglês (chaplain AND mediation AND conflict; chaplaincy AND mediation AND conflict) resultou em 219 artigos, 
demonstrando que as pesquisas nesse tema estão nitidamente voltadas à divulgação internacional.

O Quadro 2 apresenta as referências resultantes da busca nas bases de dados que atenderam aos critérios de inclusão. Além da quantidade exígua de artigos sobre o tema $(n=6)$ observa-se que apenas um deles está escrito em português e um em espanhol.

\section{Quadro 1 - Quantidade de referências encontradas nas bases de dados, de acordo com as combinações dos termos de pesquisa}

\begin{tabular}{|c|c|c|c|c|}
\hline Combinação de termos & $\begin{array}{l}\text { Portal } \\
\text { CAPES }\end{array}$ & Scielo & $\begin{array}{l}\text { Science } \\
\text { Direct }\end{array}$ & $\begin{array}{l}\text { Google } \\
\text { Acadêmico }\end{array}$ \\
\hline mediação AND conflito & 745 & 34 & 48 & 21.800 \\
\hline resolução AND alternativa AND conflitos & 316 & 7 & 92 & 18.300 \\
\hline resolução alternativa conflitos AND capelão & o & o & o & 1.460 \\
\hline resolução alternativa conflitos AND capelania & o & o & o & 1.200 \\
\hline capelão AND mediação & 2 & o & o & 2.440 \\
\hline capelão AND mediação AND conflitos & 1 & o & o & 2.010 \\
\hline capelania AND mediação & o & o & o & 2.020 \\
\hline capelania AND mediação AND conflitos & o & o & o & 1.670 \\
\hline $\begin{array}{l}\text { mediation AND conflitc } \\
\text { alternative AND dispute AND resolution AND }\end{array}$ & 39.633 & 113 & o & 269.000 \\
\hline $\begin{array}{l}\text { movement } \\
\text { alternative AND dispute AND resolution AND }\end{array}$ & 6.474 & o & 1.886 & 17.200 \\
\hline $\begin{array}{l}\text { movement AND chaplain } \\
\text { alternative AND dispute AND resolution AND }\end{array}$ & 10 & o & 1 & 16.900 \\
\hline movement AND chaplaincy & 49 & o & 6 & 14.700 \\
\hline chaplain AND mediation & 196 & o & 67 & 9.740 \\
\hline chaplain AND mediation AND conflict & 94 & o & 91 & 13.700 \\
\hline chaplaincy AND mediation & 50 & o & 34 & 1.890 \\
\hline chaplaincy AND mediation AND conflict & 23 & o & 16 & 13.800 \\
\hline
\end{tabular}

Fonte: Pesquisa dos autores. 


\section{Quadro 2 - Referências encontradas que relacionam Mediação de Conflitos e Capelania}

\section{Referência}

\section{Relação Mediação/Capelania}

ALLARD, P.; ALLARD, J. Prison A ONG Just.Equipping equipa e treina capelães de chaplaincy, restorative justice, and prisões, especificamente, nos moldes de justiça Just.Equipping. Peace Review, v. 21, n. 3, restaurativa. p. $330-338,2009$.

SCHLAIRET, M. C. Bioethics mediation: The role and importance of nursing advocacy. Nursing Outlook, v. 57, n. 4, p. 185-193, 2009.

SEALES, C. E. Corporate Chaplaincy and the American Workplace. Religion Compass, v. 6, n. 3, p. 195-203, 2012.

A autora sugere uma sequência de etapas que antecedem, ou mesmo que evitam a necessidade de mediação bioética formal na resolução de conflitos, dificuldades na tomada de decisão e dilemas éticos por parte dos pacientes e familiares.

O autor reflete sobre o papel da Capelania Corporativa. Afirma que desde a formação da indústria americana, os donos de fábricas confiaram aos ministros o papel de reforçar o moral e solucionar conflitos de seus colaboradores.

GAVRIELIDES, T. Reconciling the $\mathrm{O}$ autor esclarece que a JR existe na forma de muitas Notions of Restorative Justice and práticas, como mediação, conferência, círculos e Imprisonment. The Prison Journal, v. 94, painéis e se propõe a examinar a prática da justiça n. 4, p. 479-505, 2014. restaurativa (JR) no âmbito internacional. O artigo aponta uma série de iniciativas em diversos países. Apenas uma dessas iniciativas foi desenvolvida pelo serviço de Capelania Prisional. Projeto SORI (Supporting Offenders through Restoration Inside Inglaterra e País de Gales). 
PORTALES, L. El poder de las palabras de los capellanes. El impacto en los colaboradores de la gestión de la espiritualidad laboral. Estudios Gerenciales, v. 31, n. 135, p. 212-222, 2015.

LOPES, V. E. “O complexo para Jesus": exército e religião na ocupação militar do Complexo do Alemão. MÉTIS: história \& cultura, v. 14, n. 28, p. 219-242, 2015.
A partir de uma entrevista com capelães, familiares de colaboradores, e colaboradores de uma empresa, o autor tece comentários acerca da influência benéfica da Capelania Corporativa nos aspectos espiritual/moral, psicológico, profissional e familiar dos colaboradores. Entretanto, observa a necessidade de uma abertura do colaborar e de seus familiares para a interferência de um capelão, quando se trata de uma relação conflituosa intrafamiliar.

A partir de um trabalho etnográfico o autor descreve como o comando do Exército Brasileiro desenvolveu estratégias de pacificação do Morro do Alemão (RJ) entendendo que atores religiosos locais (capelães militares e civis) poderiam desempenhar um papel importante na mediação das relações tensas entre soldados e moradores.

Fonte: Pesquisa dos autores.

A Justiça Restaurativa é abordada no contexto de Ruanda pós-genocídio, onde os autores (ALLARD; ALLARD, 2009) abordam as dificuldades em lidar com os encarcerados. $\mathrm{O}$ artigo descreve a impressionante determinação dos capelães carcerários de Ruanda que vão para as prisões sempre que podem, apesar de não receber nenhum salário e nenhum subsídio de transporte. Esses capelães vão para essas prisões, embora eles mesmo estejam em luta constante para prover sua família de alimentos, saúde e educação. Eles vão sabendo que os prisioneiros vão implorar por comida ou medicamentos que eles não têm para oferecer. 
Os autores apontam que os capelães carcerários visitam os prisioneiros cientes do fato de que muitas das pessoas que eles veem não foram oficialmente acusadas de um crime e permanecerão encarceradas por anos sem advogado ou julgamento. Segundo os autores eles vão porque sabem que Deus ama cada desses homens e mulheres. E muito embora a vontade de ajudar a todos estivesse presente nas atitudes dos capelães eles se encontravam desmotivados por não terem conhecimento de "como" poderiam ser mais úteis e eficientes em suas ações. Foi nesse cenário que a ONG Just.Equipping encontrou-os e ofereceu treinamento básico em justiça a trinta capelães de Ruanda, Burundi e RD Congo. O treinamento aconteceu em dois momentos distintos: 1) ano de 2007 foram discutidas as raízes da violência, o processo de desumanização, demonização e crimes de ódio e, 2) no ano seguinte a Just.Equipping retornou para ministrar um treinamento mais avançado com foco em aconselhamento pastoral, cuidado pastoral e ministério de escuta e acompanhamento, além do ministério de pregação.

Dentre os tópicos ministrados, a ONG Just.Equipping criou um módulo de ensino intitulado "Cultivando a Paz: Um Protocolo para Reuniões de DelinquentesVítimas em uma Perspectiva da Justiça Restaurativa" para treinar os capelães a mediar o encontro entre vítimas e ofensores. Este treinamento em Capelania, baseado na justiça restaurativa, produziu resultados significativos - para os capelães, os infratores e suas vítimas, bem como para a comunidade.

A experiência relatada nesse artigo revela o quanto a determinação e dedicação são ingredientes necessários à atuação dos capelães, em particular no setor carcerário, por apresentar desafios ainda maiores, bem como demonstra a necessidade de um treinamento específico, e o quanto essa capacitação pode potencializar ações mais eficazes. Segundo informações contidas no site da Just.Equipping, eles continuam sua missão de enviar equipes de ensino constituídas de 4-5 pessoas para países em desenvolvimento para sessões de treinamento intensivo; levam para o Canadá um pequeno número de líderes para se beneficiar das sessões anuais de Justiça Restaurativa na Queen's University, em Kingston, Ontário. Uma das características importantes da Just.Equipping é a sua 
parceria com o Queen's Theological College, da Queen's University. Por causa dessa parceria, um Diploma Internacional em Justiça Restaurativa pode ser concedido a todos os interessados que atendem aos cursos oferecidos.

O artigo sobre mediação biotética (SCHLAIRET, 2009), apesar da ênfase na atuação da equipe de enfermagem nos Comitês Bioéticos dos centros de saúde, apresenta uma visão abrangente dos modelos que auxiliam na tomada de decisão quanto aos conflitos na escolha do tratamento. A autora aponta dois grandes modelos de serviços de consulta ética (SCE), o Modelo de Consulta Bioética e o Processo de Mediação Bioética.

O Modelo de Consulta Bioética é um modelo tradicional e largamente utilizado, cujo objetivo é elaborar, a partir da opinião de especialistas, um parecer norteador das condutas clínicas. O Processo de Mediação Bioética contrasta com o Modelo de Consulta Bioética por ser um modelo facilitador, no qual as habilidades interpessoais, mediativas, de conflito e de resolução de disputas são combinadas com princípios éticos em um processo único para identificar e resolver dilemas éticos que surgem nos contextos de saúde. As etapas percorridas nesse processo vão desde a Análise inicial da situação até o acompanhamento das soluções propostas.

No artigo são apresentados e analisados dois casos, elaborados a partir de situações reais, de aplicação do Processo de Mediação Bioética gerenciados pela equipe de enfermagem de um hospital. O que chama a atenção no artigo e que apresenta elação com o tema do presente estudo está relatado no caso $1 . \mathrm{Na}$ descrição desse caso observa-se o relato da atuação da equipe de enfermagem, que gerenciou uma situação de conflito entre familiares de uma paciente que apresentava um prognóstico sombrio quanto as suas condições de saúde. A análise inicial da situação demonstrou haver um conflito entre os familiares da paciente e seu marido, que se estendeu a toda equipe médica. Após a identificação dos conflitos interpessoais, a equipe de enfermagem encaminhou os familiares ao serviço de Capelania do hospital. Segundo a autora, o contato com o capelão 
permitiu que a família identificasse e abordasse os conflitos emocionais e interpessoais que estavam influenciando suas percepções e dificultando a tomada de decisões.

Apesar de o artigo apresentar um relato sucinto da atuação do capelão observa-se que o momento de sua atuação no processo é de fundamental importância, pois somente a partir da identificação e solução dos conflitos interpessoais foi possível avançar na tomada de decisões. Nesse contexto a atuação do capelão foi não somente de acolhimento espiritual e aconselhamento, mas também, como membro da equipe hospitalar e com uma atuação integrada ao Processo de Mediação Bioética o capelão foi capaz de intervir beneficamente numa situação de conflito associada a um ambiente hospitalar.

A Capelania Corporativa ou Capelania Empresarial é abordada no estudo de Chad E. Seales (SEALES, 2012). O autor apresenta o ramo da Capelania Corporativa como uma atividade em expansão nos Estados Unidos. O papel da capelania industrial, no século XX, apresentou aspectos negativos quando de sua influência com o foco maciço na produtividade dos funcionários. Entre os mais influentes no desenvolvimento capelania industrial estava o ministro batista, George D. Heaton, que de 1939 a 1996, orientou os fabricantes sobre como aumentar a produtividade do trabalhador por meio de estratégias de gerenciamento semelhantes às de Cristo. Ele considerava Jesus como um modelo de Surpervisor e declarou o processo industrial como um milagre que a vida moderna pode testemunhar.

Embora na atualidade a maioria dos americanos não trabalhe mais em indústrias, observam-se resquícios da atuação da Capelania industrial. Em 2007, a Tyson Foods empregou cento e vinte capelães em setenta e sete instalações de produção diferentes; em 2011, a Marketplace Chaplains, uma empresa de recrutamento de pessoal de capelania fundada em Dallas, Texas, em 1984, capacitou 2.482 capelães para mais de 500.000 funcionários em empresas em 850 cidades nos Estados Unidos. Já a empresa Capelania Corporativa da América, com 
sede em Raleigh, Carolina do Norte, teve como meta o treinamento de milhares de capelães para atenderem milhões de pessoas em 2012. Segundo o autor a demanda por capelães corporativos tem relação direta com a produtividade das empresas, pois se constatou que a atuação do capelão entre os funcionários aumenta as margens de lucro e permite que as empresas obtenham mais lucro com menos gastos.

O autor conclui com uma crítica a atuação dos capelães corporativos, pois na sua visão eles serviam para produzir e promover uma religião industrial, ou seja, aquela que aproxima a espiritualidade dos aspectos econômicos, uma parceria com o capitalismo consumista nas sociedades pós-industriais. No presente estudo não encontramos nenhum artigo sobre a Capelania Empresarial no Brasil, entretanto, numa busca em sites não acadêmicos nos deparamos com o estatuto da "Associação +1 Capelania Empresarial no Brasil”, com data de Registro em Cartório de 29 de dezembro de 2015 (Americana - SP). A área de Capelania Corporativa parece ser um campo fértil de investimento e investigação para capelães interessados na área corporativa.

Theo Gavrielides (GAVRIELIDES, 2014) em seu estudo sobre a Justiça Restaurativa nas prisões explica que a JR pode ser praticada de diferentes formas, como mediação, conferência, círculos e painéis. O autor examina a prática da justiça restaurativa no âmbito internacional listando uma série de iniciativas desse porte em diversos países. O que chama a atenção nesse estudo é que apenas uma dessas iniciativas citadas foi desenvolvida pelo serviço de Capelania Prisional (Projeto SORI - Supporting Offenders through Restoration Inside - Inglaterra e País de Gales). Não há uma descrição detalhada sobre o projeto.

Portales (2015), a partir de uma entrevista com capelães, familiares de colaboradores, e colaboradores de uma empresa, analisa a influência benéfica da Capelania Corporativa nos aspectos espiritual/moral, psicológico, profissional e familiar dos colaboradores de uma empresa do México. Entretanto, o autor aponta a limitação de atuação do capelão quando se trata de conflitos intrafamiliares, pois 
sua intervenção depende da abertura do colaborar e de seus familiares para a interferência de um capelão.

O artigo etnográfico de Lopes (2015) descreve como o comando do Exército Brasileiro desenvolveu estratégias de pacificação do Complexo do Alemão (RJ) entendendo que atores religiosos locais (capelães militares e civis) poderiam desempenhar um papel importante na mediação das relações tensas entre soldados e moradores. Entretanto, por diversas questões, inclusive a falta de organização, o projeto não foi adiante, sendo interrompido quando o Exército Brasileiro deixou o Complexo do Alemão, em cerimônia pública e a tutela do gabinete foi transmitida à Polícia Militar.

\section{Considerações finais}

Em Lc 12:58, 59 lê-se: "Quando algum de vocês estiver indo com seu adversário para o magistrado, faça tudo para se reconciliar com ele no caminho; para que ele não o arraste ao juiz, o juiz o entregue ao oficial de justiça, e o oficial de justiça o jogue na prisão. Eu digo que você não sairá de lá enquanto não pagar o último centavo". Claramente trata-se de uma admoestação quanto ao juízo final e a necessidade de o homem reconciliar-se com Deus antes do ajuste de contas. Entretanto, como os ensinamentos bíblicos servem tanto como metáfora sobre o Reino como para a edificação do ser humano durante sua existência terrena, podemos tomar esse trecho como um ensinamento acerca dos conflitos interpessoais, pois, da mesma forma que o pecador que não se reconciliar com Deus receberá a justa sentença, o homem que agiu incorretamente para com o seu próximo, em sendo levado perante o juiz humano sofrerá as consequências. Entretanto, tudo pode ser resolvido antes de chegar ao magistrado, mesmo que seja necessária a ajuda de uma terceira pessoa.

Embora a busca de uma convivência harmoniosa com todos seja o anseio de todos, os conflitos fazem parte dos relacionamentos entre as pessoas e propiciam o desenvolvimento dos ajustes necessários para a convivência. $O$ transtorno 
emocional advindo da situação conflituosa pode dificultar, e até mesmo impedir, a resolução de uma contenda, sendo imperiosa a intervenção de uma terceira pessoa que não esteja diretamente envolvida, e que se aplique em facilitar e estabelecer o diálogo entre as partes. Essa mediação deve conduzir a todos a uma reflexão e colaboração na busca de uma solução. O Capelão é uma figura de posição privilegiada para ajudar no estabelecimento do diálogo em situações de conflito, em particular para as pessoas que se identificam com o sagrado como elemento do seu cotidiano, seja no âmbito familiar ou no trabalho.

Diante dos artigos analisados nesse estudo foi possível identificar poucas propostas dos serviços ou setores de Capelania para a mediação de conflitos. No levantamento realizado nesse estudo as iniciativas apresentaram características distintas, isto é, no ambiente prisional, hospitalar e corporativo. Além disso, chama a atenção que apenas em uma delas houve um preparo específico dos capelães para mediação. Trata-se da atuação da ONG Just.Equipping na capacitação de capelães prisionais. A experiência relatada nesse artigo demonstra a necessidade de um treinamento específico, e o quanto essa capacitação pode potencializar ações mais eficazes.

O processo de mediação informal tem sido incentivado de modo minimizar os danos psicológicos e reduzir o tempo para a solução das situações de conflitos interpessoais, visto que a mediação formal pode ser morosa e trazer desconforto dos conflitantes com o ambiente judicial. Contudo, ainda é controverso na literatura se a atuação do terceiro facilitador deve ser neutra ou multiparcial. No caso específico da atuação do capelão/aconselhador como mediador fica clara a presença de um viés religioso que não pode ser ignorado, pois é inegável a influência da religiosidade/espiritualidade no processo de acolhimento do capelão, e aqueles que buscam conforto, acolhimento e auxílio para solução de conflitos na figura do capelão geralmente são pessoas que encontram o Sagrado nas situações do dia-a-dia. Nesse aspecto vale salientar que se trata de um viés religioso/espiritual e não denominacional e dogmático. Pode-se dizer que é esperada uma conduta multiparcial baseada na busca do bem-estar das pessoas 
envolvidas no conflito, sem haver, contudo, tendência de privilegiar um ou outro. Essa capacidade de apoiar sem pender para nenhum lado fala a favor de uma credibilidade e confiança na figura do capelão mediador, sendo essa uma condição fundamental para o sucesso no processo de mediação.

Quando se transporta o processo de mediação para a atuação do capelão/aconselhador observamos que não há literatura disponível que apresente elementos teóricos específicos associando o processo de mediação informal ao papel do capelão, sendo necessário àqueles que apresentem interesse em aprimorar-se nesse sentido, recorrer aos cursos de capacitação dos terceiros facilitadores, que apesar de apresentarem Diretrizes Curriculares peculiares, não apresentam direcionamento específico para a área da Capelania e Aconselhamento. Da mesma forma os cursos de Aconselhamento e Capelania, de modo geral, apesar de apresentarem conteúdo específico sobre os conflitos interpessoais, não apresentam informações relacionadas ao processo de mediação. A partir desse estudo consideramos que o tema abordado abre portas para reflexões, discussões e pesquisas sobre atuação do Capelão como Mediador.

\section{REFERÊNCIAS}

ALLARD, Pierre; ALLARD, Judy. Prison chaplaincy, restorative justice, and just equipping. Peace Review, Abingdon, v. 21, n. 3, p. 330-338, 2009.

ALVES, Gisleno Gomes de Faria. Manual do capelão: teoria e prática. São Paulo: Hagnos, 2017.

ASSOCIAÇÃO DE CAPELANIA DO BRASIL. Disponível em: http://www.capelaniadobrasil.com.br/capelanias/ Acesso em: 14 de maio de 2018.

AZEVEDO, André Gormma de. Manual de mediação judicial. 6. ed. Brasília, DF: CNJ, 2016.

BERCOVITCH, Jacob. Mediators and mediation strategies in international relations. Negotiation Journal, Chichester, v. 8, n. 2, p. 99-112, 1992. 
BÍBLIA. A bíblia sagrada: contendo o velho e o novo testamento. Rio de Janeiro: Sociedade Bíblica do Brasil, 2000.

BRAGA NETO, Adolfo. Mediação de conflitos: princípios e norteadores. Revista da Faculdade de Direito UniRitter, Porto Alegre, n. 11, p. 29-46, 2010.

BRASIL. Lei $\mathrm{n}^{0} 13.140$ de 26 de Junho de 2015. Dispõe sobre a mediação entre particulares como meio de solução de controvérsias e sobre a autocomposição de conflitos no âmbito da administração pública; altera a Lei no 9.469, de 10 de julho de 1997, e o Decreto no 70.235, de 6 de março de 1972; e revoga o § 20 do art. 60 da Lei no 9.469, de 10 de julho de 1997.Diário Oficial da república Federativa do Brasil. Brasília, DF, 26 jun. 2015. https://www.jusbrasil.com.br/topicos/47616780/artigo-11-da-lei-n-13140-de-26-dejunho-de-2015. Acesso em: 14 out. 2015.

DIAS, Rogério Correia. Mediação de conflitos. Momentum, Atibaia, v. 1, n. 12, p. 179-182, 2014 .

DOMINGOS, Graça; FREIRE, Isabel. Gestão de conflitos e competências da mediação informal. Revista Galego-Portuguesa de Psicoloxía Educación, Coruña, v. 17, n. 1, p. 85-97, 2009.

FALECK, Diego; TARTUCE, Fernanda. Introdução histórica e modelos de mediação. Estudos avançados de mediação e arbitragem. Rio de Janeiro: Campus Jurídico, 2014.

FRADE, Catarina. A resolução alternativa de litígios e o acesso à justiça: A mediação do sobreendividamento. Revista Crítica de Ciências Sociais, Coimbra, n. 65, p. 107-128, 2003.

GAVRIELIDES, Theo. Reconciling the notions of restorative justice and imprisonment. The Prison Journal, Filadelfia, v. 94, n. 4, p. 479-505, 2014.

GIESSMANN, Hans J.; WILS, Oliver. Seeking compromise? Mediation through the eyes of conflict parties. In: AUSTIN, Beatrix; FISCHER, Martina; GIESSMANN, Hans J. (ed.). Advancing conflict transformation: the Berghof handbook II. Farmington Hills: Barbara Budrich Publishers, 2011. p. 183-206.

LAURSEN, Brett; HARTL, Amy C. Conflict and socioemotional development. In: WRIGHT, James D. (ed.). International encyclopedia of the social \& behavioral sciences. Palo Alto: Elsevier, 2015.

LAURSEN, Brett; HARTUP, Willard W.; KOPLAS, Ann L. Towards understanding peer conflict. Merrill-Palmer Quarterly (1982-), Detroit, p. 76-102, 1996.

LOPES, Vinícios Esperança. “O complexo para Jesus”: exército e religião na ocupação militar do Complexo do Alemão. Métis: história \& cultura, Caxias do Sul, v. 14, n. 28, 2015 . 
PORTALES, Luis. El poder de las palabras de los capellanes. El impacto en los colaboradores de la gestión de la espiritualidad laboral. Estudios Gerenciales, Cali, v. 31, n. 135, p. 212-222, 2015.

RETZINGER, Suzanne; SCHEFF, Thomas. Emotion, alienation, and narratives: Resolving intractable conflict. Mediation Quarterly, Chichester, v. 18, n. 1, p. 71-85, 2000.

ROTHMAN, Jay. The reflexive mediator. Negotiation Journal, Chichester, v. 30, n. 4, p. 441-453, 2014.

SCHLAIRET, Maura C. Bioethics mediation: the role and importance of nursing advocacy. Nursing Outlook, Filadelfia, v. 57, n. 4, p. 185-193, 2009.

SEALES, Chad E. Corporate chaplaincy and the American workplace. Religion

Compass, Chichester, v. 6, n. 3, p. 195-203, 2012.

SERRANO, Gonzalo. ¿ Qué dice la investigación científica sobre mediación? Madrid: Colegio Oficial de Psicólogos de Madrid, 1996.

SOUZA, Edilson Soares. Aconselhamento pastoral: reflexões em torno do sagrado. Via Teológica, Curitiba, v. 14, n. 28, p. 105-126, dez. 2013.

SPENGLER, Fabiana Marion; MORAIS, Jose Luis Bolzan de. Mediação e arbitragem: alternativas à jurisdição. Porto Alegre: Livraria do Advogado, 2018.

TORRACO, Richard J. Writing integrative literature reviews: guidelines and examples. Human Resource Development Review, Saint Paul, v. 4, n. 3, p. 356-367, 2005 .

WILLEY, Frank T. The chaplain as mediator: a ministry of presence and productivity. Care Giver, Abingdon, v. 6, n. 1, p. 77-89, 1989. 